\title{
O USO DO GEOGEBRA PODE POTENCIALIZAR O ENSINO- APRENDIZAGEM DAS FUNÇÕES LOGARÍTMICAS?
}

\section{MARCUS TÚLIO DE FREITAS PINHEIRO}

Universidade do Estado da Bahia (UNEB). Doutor em Ciência da Educação (UFBA). Mestrado em Engenharia de Produção (UFSC). Especialização em Educação e Tecnologia da Informação (UFBA). Graduação em Física pela UFBA. Grupo de Pesquisa: Educação, Tecnologias, Difusão do Conhecimento e Modelagens de Sistemas Sociais - DCETM UNEB/CNPq. ORCID: 0000-

0003-1170-3644. E-mail: mtuliop@gmail.com

\section{ANDRÉ RICARDO MAGALHÃES}

Universidade do Estado da Bahia (UNEB). Doutor em Educação Matemática (PUC/ SP). Mestre em Engenharia de Produção (UFSC). Especialista em Educação e Novas Tecnologias da Informação e da Comunicação (UNEB). Bacharel em Informática (UCSal).

Grupo de Pesquisa: Tecnologias Inteligentes e Educação - TECINTED UNEB/CNPq. ORCID: 0000-0001-9600-0918. E-mail: andrerm@gmail.com

\section{KARINE SOCORRO PUGAS DA SILVA}

Instituto Federal de Educação, Ciência e Tecnologia da Bahia (IFBA). Mestra em Gestão e Tecnologias Aplicadas à Educação (UNEB). Professora do Instituto Federal de Educação, Ciência e Tecnologia da Bahia (IFBA) - Campus Camaçari. Grupo de Pesquisa Educação, Tecnologias, Difusão do Conhecimento e Modelagens de Sistemas Sociais - DCETM UNEB/ CNPq. ORCID: 0000-0001-8538-6640.E-mail:helppugas@gmail.com 


\section{O USO DO GEOGEBRA PODE POTENCIALIZAR O ENSINO-APRENDIZAGEM DAS FUNÇÕES LOGARÍTMICAS?}

Diante das dificuldades encontradas, ao longo do processo de ensino da disciplina Introdução à Matemática, houve a necessidade de se repensar sobre a práxis pedagógica e quais os entraves encontrados nesse processo de apropriação do conhecimento matemático. Este trabalho, fruto da pesquisa de mestrado, ocorreu no Instituto Federal de Educação, Ciência e Tecnologia da Bahia (IFBA), campus Camaçari, com alunos do primeiro semestre de Licenciatura em Matemática. Esse estudo teve como objetivo analisar como o GeoGebra pode potencializar o ensino-aprendizagem das funções logarítmicas. Como resposta a esse objetivo, houve a necessidade da construção, aplicação e análise de sequências didáticas com o uso desse software. A metodologia utilizada, de caráter qualitativa, consistiu em algumas etapas. Primeiro, realizou-se uma entrevista guiada com quatro grupos focais, a qual forneceu subsídios para elaboração de uma sequência didática, referendada pela Teoria das Situações Didáticas (TSD), de Guy Brousseau. Nesta sequência foi aplicada com o grupo de alunos e posteriormente analisada. Para as análises de todo o processo, desde a aplicação até os resultados obtidos, utilizou-se da Engenharia Didática. Os resultados da análise da aplicação dessa sequência didática e o questionário respondido pelos discentes sugerem que o uso do GeoGebra contribuiu de forma significativa para o ensino-aprendizagem das funções logarítmicas. Dessa forma, a escolha da TSD e o uso do GeoGebra não se resume à uma técnica para corroborar na aprendizagem de conteúdos matemáticos, mas é ampliada pela necessidade de formar cidadãos conscientes no seu papel como atores transformadores da sociedade, onde a reflexão e o pensamento crítico seja o objetivo final.

Palavras-chave: Funções Logarítmicas. GeoGebra. Engenharia Didática. Teoria das Situações Didática.

\section{¿PUEDE EL USO DE GEOGEBRA MEJORAR LA ENSEÑANZA-APRENDIZAJE DE LAS FUNCIONES LOGARÍTMICAS?}

En vista de las dificultades encontradas, a lo largo del proceso de enseñanza de la disciplina Introducción a las Matemáticas, hubo una necesidad de repensar sobre la praxis pedagógica y cuáles son los obstáculos encontrados en este proceso de apropiación del conocimiento matemático. Este trabajo, resultado de una investigación de maestría, tuvo lugar en el Instituto Federal de Educación, Ciencia y Tecnología de Bahía (IFBA), campus de Camaçari, con estudiantes del primer semestre de una Licenciatura en Matemáticas. Este estudio tuvo como objetivo analizar cómo GeoGebra puede mejorar la enseñanza-aprendizaje de las funciones logarítmicas. En respuesta a este objetivo, era necesario construir, aplicar y analizar secuencias didácticas utilizando este software. La metodología utilizada, de carácter cualitativo, consistió en algunas etapas. Primero, se realizó una entrevista guiada con cuatro grupos focales, que proporcionaron subsidios para la elaboración de una secuencia didáctica, respaldada por la Teoría de situaciones didácticas (TSD) de Guy Brousseau. En esta secuencia se aplicó con el grupo de estudiantes y luego se analizó. Para el análisis de todo el proceso, desde la aplicación hasta los resultados obtenidos, se utilizó la Ingeniería Didáctica. Los resultados del análisis de la aplicación de esta secuencia didáctica y el cuestionario respondido por los estudiantes sugieren que el uso de GeoGebra contribuyó significativamente a la enseñanza-aprendizaje de las funciones logarítmicas. Por lo tanto, la elección de TSD y el uso de GeoGebra no se limita a una técnica para apoyar el aprendizaje de contenido matemático, sino que se amplifica por la necesidad de capacitar a ciudadanos conscientes en su papel como actores transformadores en la sociedad, donde la reflexión y el pensamiento crítico es el objetivo final.

Palabras clave: Funciones logarítmicas. GeoGebra. Ingeniería Didáctica. Teoría de situaciones didácticas. 


\section{CAN THE USE OF GEOGEBRA ENHANCE THE TEACHING-LEARNING OF LOGARITHMIC FUNCTIONS?}

In view of the difficulties encountered, throughout the teaching process of the Introduction to Mathematics discipline, there was a need to rethink about pedagogical praxis and what are the obstacles encountered in this process of appropriating mathematical knowledge. This work, the result of a master's research, took place at the Federal Institute of Education, Science and Technology of Bahia (IFBA), Camaçari campus, with students from the first semester of a Mathematics Degree. This study aimed to analyze how GeoGebra can enhance the teaching-learning of logarithmic functions. In response to this objective, there was a need to build, apply and analyze didactic sequences using this software. The methodology used, of qualitative character, consisted of some stages. First, a guided interview was conducted with four focus groups, which provided subsidies for the elaboration of a didactic sequence, endorsed by Guy Brousseau's Theory of Didactic Situations (TSD). In this sequence it was applied with the group of students and later analyzed. For the analysis of the entire process, from application to the results obtained, Didactic Engineering was used. The results of the analysis of the application of this didactic sequence and the questionnaire answered by the students suggest that the use of GeoGebra contributed significantly to the teaching-learning of logarithmic functions. Thus, the choice of TSD and the use of GeoGebra is not limited to a technique to support the learning of mathematical content, but it is amplified by the need to train conscious citizens in their role as transforming actors in society, where reflection and thinking critical is the ultimate goal.

Keywords: Logarithmic functions. GeoGebra. Didactic Engineering. Theory of Didactic Situations. 


\section{O USO DO GEOGEBRA PODE POTENCIALIZAR O ENSINO- APRENDIZAGEM DAS FUNÇÕES LOGARÍTMICAS?}

\section{Introdução}

Essa pesquisa, fruto da dissertação do Mestrado Profissional, surgiu a partir das inquietações originadas durante as aulas de matemática, em uma turma da Licenciatura em Matemática, no campus Camaçari do Instituto Federal de Educação, Ciência e Tecnologia da Bahia. Diante das dificuldades encontradas, ao longo do processo de ensino da disciplina Introdução à Matemática, houve a necessidade de se repensar sobre a práxis pedagógica e quais os entraves encontrados nesse processo de apropriação do conhecimento matemático.

Para isso, o objeto de estudo escolhido foi a função logarítmica, através da observação e mapeamento das dificuldades dos discentes e de seus conhecimentos prévios sobre o tema.

Ao analisar os feedbacks durante as aulas e o desempenho dos alunos nas avaliações, verificou-se alguns obstáculos durante o processo de ensino-aprendizagem dessa função em particular. Os empecilhos encontrados foram referentes à localização de pontos no plano cartesiano, dificuldade de entender a linguagem formal da matemática, apropriação das operações de potenciação e de radiciação, a linguagem algébrica e por fim, a representação gráfica.

Num mundo globalizado, não cabe mais a concepção de que o professor é um mero transmissor de conhecimentos e o aluno um "anotador" de conteúdo, ficando este último reduzido a um repetidor de modelos ou solucionador de "determinados" problemas. Algumas pesquisas apontam que a metodologia tradicional de ensino (definição, demonstração de propriedades, exemplos e exercícios de fixação) não desperta mais o interesse do aluno.

$\mathrm{Na}$ Era do Conhecimento, torna-se indispensável o repensar da prática pedagógica, é necessário pesquisar os porquês das deficiências e como podemos resolvê-las. Compartilhando da ideia de D’Ambrosio (2012, p.73) de que "o novo papel do professor será o de gerenciar, de facilitar o processo de aprendizagem e, naturalmente, de interagir com o aluno na produção e na crítica de novos conhecimentos [...]", essa pesquisa se propôs a ouvir os discentes, mapear alguns dos seus 
conhecimentos prévios e a partir dessas informações traçar um plano de ação. Através da escolha do software GeoGebra tenta-se alcançar o objetivo específico de elaborar situações didáticas e posteriormente aplicá-las e analisá-las com o auxílio da Engenharia Didática.

Nesse sentido, o suporte tecnológico, no presente trabalho, consiste numa hibridização de duas concepções centrada no processo e como estratégia de inovação, ao descrevê-la como um conjunto de esforços intelectuais e/ou operacionais com o objetivo de sistematizar ou reorganizar a aplicação de novas teorias, conceitos, ideias, técnicas ou aplicações, de modo a potencializar os processos de ensino-aprendizagem, com a intenção de proporcionar ao discente fazer novas leituras sobre um determinado tema.

Surge a necessidade de uma profunda reflexão pedagógica para contribuir como ator desse processo em construção com alguns avanços que venham a despertar nos docentes a consciência de que a tecnologia é uma alternativa que já faz parte do nosso dia-a-dia. Esse é o fator propulsor que cada educador no mundo contemporâneo deve se conscientizar em busca de uma nova postura na arte de educar, de transformar o conhecimento de forma estimulante, numa necessidade de novos saberes. A necessidade de incorporação das tecnologias dentro do ambiente de ensino-aprendizagem torna-se extremamente essencial por ampliar as possibilidades de construção do conhecimento matemático e reorganização do pensamento.

$\mathrm{O}$ artigo tem como norte desvendar ou ao menos investigar como o suporte tecnológico do GeoGebra pode potencializar o ensino das funções logarítmicas e para obter tais respostas, alguns diálogos teóricos foram realizados.

\title{
Desenvolvimento
}

Os principais obstáculos no ensino das funções na disciplina de Cálculo, segundo Nasser (2015), são a concepção ingênua do aluno ao considerar que: o gráfico que representa uma função não precisa ser exato, a crença de que o gráfico que representa uma função é obtido marcando alguns pontos no plano cartesiano e unindo-os por segmentos de reta, deixando de considerar a lei de formação da função; as dificuldades na transposição da representação verbal (descrição da situação problema) para uma representação analítica; as dificuldades na transposição da representação verbal para uma representação gráfica; as dificuldades em questões de máximos e

\author{
plurais


mínimos e a concepção de que "apenas relações representáveis por fórmulas analíticas são dignas de serem chamadas funções”. De fato, muitos alunos só reconhecem como funções as relações que são representadas por uma expressão algébrica, e apresentam dificuldades, por exemplo, ao lidar com funções definidas por várias sentenças.

A importância do uso de softwares gráficos na pesquisa é justificada pela exploração de possibilidades de representações múltiplas que o aporte tecnológico oportuniza, que pode ser confirmado por Allevato (2010, p. 113) onde para ela "alguns softwares permitem passar de representações algébricas para representações gráficas com muita facilidade e rapidez". A mesma autora ainda fortalece a importância do uso do suporte tecnológico quando afirma que "permitem ao aluno conectar conhecimentos que, de outra forma, permaneceriam separados; porém, se conectados, geram compreensões matemáticas mais amplas e completas” (ALLEVATO, 2010, p. 124).

Segundo o conceito de "virtual" elaborado por Lévy (2011) pode-se dizer que os softwares matemáticos gratuitos possuem uma "virtualidade de mudança", pois no momento em que os estudantes são incentivados e/ou provocados a resolver um problema do cotidiano, utilizando essas ferramentas e trabalhando em grupo, temos um "complexo problemático", conflitos, dinâmicas de colaboração, o surgimento de novas competências e habilidades que através de um "processo de resolução" se "atualiza de maneira mais ou menos inventiva".

Em conformidade com os artigos de Reis (2015), Rocha (2010) e Batista (2004), a utilização de softwares matemáticos proporciona ao aluno: a visualização, modelagem, simulações, conexões, experimentos e conjecturas em gráficos que representam uma determinada função. É nesse ambiente tecnológico que ele tem a oportunidade de se expressar, visualizar, confrontar e remodelar suas ideias anteriores sobre as funções e até mesmo desenvolver novos conceitos de funções. Dessa forma, a exploração de possibilidades mediante o uso de softwares gráficos na pesquisa é justificada.

A escolha do GeoGebra, software gratuito de Matemática Dinâmica, criado por Markus Hohenwarter, para aplicar a Sequência Didática foi pautada em suas principais vantagens: permissão de uso sem custo; disponível em português, multiplataforma, interface de fácil manuseio; a não necessidade de conhecimentos prévios sobre linguagem de programação; vários recursos interconectados e dinâmicos, que permitem possibilidades de representações de um mesmo objeto e o

\section{plurais}

Salvador, v. 5, n. 2, p. 78-96, mai./ago. 2020 
fato de englobar, em um único ambiente, ferramentas de Geometria, Estatística, Cálculo, Álgebra Linear, dentre outras.

Corroborando com Borba e Penteado (2003, p. 43), "O enfoque experimental explora ao máximo as possibilidades de rápido feedback das mídias informáticas”, dessa forma, com a utilização desse software, pretende-se proporcionar várias possibilidades para que os estudantes possam investigar ou criar estratégias de resolução de determinada sequência didática e testar hipóteses, oportunizando visões ampliadas além do ambiente lápis e papel.

O estudo de funções é justificado por sua grande importância na nossa vida cotidiana (seja ao decidir qual a melhor promoção de companhias de telefone móvel, ou no imposto de renda em função do rendimento, o preço a pagar em função da quantidade de mercadoria adquirida, variação de capital aplicado a juros fixos, entre outros), como em outras áreas da própria Matemática (Financeira, Análise, Cálculo Numérico, Equações Diferenciais) e em outras áreas do conhecimento nas suas diversas aplicações.

Segundo Lima et al (2006, p. 81), muitos livros didáticos trazem a definição de função, como um subconjunto de um determinado produto cartesiano. E para ele essa definição traz alguns prejuízos à compreensão da noção intuitiva que deveria ser mais trabalhada com os educandos. Para este autor, o importante é compreender a função como "correspondência, transformação, dependência (uma grandeza função de outra) ou resultado de um movimento."

Para o embasamento teórico foram escolhidas a Teoria das Situações Didáticas (TSD), desenvolvida por Guy Brousseau, na década de 70, justificada por propor uma interligação entre aprendiz, professor e o meio (no qual acontecem a difusão e aquisição de conhecimentos) e a Engenharia Didática para analisar todo o processo de planejamento, elaboração, aplicação e resultados da Sequência Didática.

Para Almouloud (2007), o foco principal da TSD é verificar no processo de ensino- aprendizagem as situações que possam ser reproduzidas e possibilitem a modificação de comportamento dos docentes (aquisição de novos conhecimentos), decorrente de uma aprendizagem significativa.

A situação didática de aprendizagem dessa pesquisa foi elaborada com o propósito de possibilitar a apropriação de conhecimentos matemáticos referentes às funções logarítmicas aos alunos

\section{plurais}


de Licenciatura, promovendo reflexões nos autores frente às etapas propostas por Brousseau (2008): ação, formulação, validação e institucionalização. Na ação, é proposto o problema, o aluno reflete e "simula tentativas", através da retroalimentação do meio, tomando as decisões que faltam para organizar a resolução do problema. Na fase seguinte, a formulação é caracterizada pela troca de informação entre o aluno e o meio (ou entre os alunos e o meio) sobre o problema.

Na validação, o aluno organiza os enunciados, e tem a oportunidade de provar a validade do seu modelo para os interlocutores. Essas três fases caracterizam a situação adidática, "onde o professor permite ao aluno trilhar os caminhos da descoberta, não revelando ao aluno sua intenção didática, tendo somente o papel de mediador". (POMMER, 2008, p. 8).

Por fim, acontece a institucionalização do saber. Essa etapa é realizada pelo professor, e, segundo Almouloud (2007) com o objetivo de oficializar o saber, possibilitando que os alunos incorporem "a seus esquemas mentais" os novos conhecimentos e que possam estruturá-los e posteriormente, utilizá-los em novas resoluções de problemas matemáticos.

A TSD se preocupa como determinado conteúdo matemático será abordado pelo professor diante da relação pedagógica estabelecida com seus alunos, possibilitando uma aprendizagem significativa para o aprendiz. Para atender a esses objetivos surge a necessidade de um "contrato didático", que, para Brousseau (2008, p. 74), é uma relação entre professor e aluno na qual existe tacitamente uma expectativa de cada um dos atores sociais de um conjunto determinado de comportamento.

Como metodologia de análise foi utilizada a Engenharia Didática que de acordo com Almouloud (2007) despontou a partir da Didática Francesa no início dos anos 80, apresentando três fases bem definidas: análises prévias, construção das situações e análise a priori, e experimentação, análise a posteriori e validação.

Em consonânica com Almouloud (2007, p. 171), quando ele considera a Engenharia Didática como uma metodologia de pesquisa e a caracteriza como:

[...] um esquema experimental com base em "realizações didáticas" em sala de aula, isto é, na construção, realização, observação e análise de sessões de 
ensino.[...]pelo registro em que se situa e pelos modos de validação que lhe são associados: a comparação entre análise a priori e análise a posteriori. [...] validação é uma das singularidades dessa metodologia, por ser feita internamente, sem a necessidade de aplicação de um pré-teste ou de um pósteste. (Almouloud, 2007, p. 171)

A análise prévia dessa pesquisa se caracterizou pelo estudo dos sujeitos da pesquisa (o perfil e os conhecimentos prévios em Matemática e Informática), através da Entrevista Guiada com Grupos Focais. Com o objetivo de identificar os principais problemas de ensino- aprendizagem das Funções Logarítmicas.

Na fase de construção da sequência, conforme Almouloud (2007, p. 174), o pesquisador constrói e analisa a sequência didática de "situações-problema." De acordo com Pais, uma sequência didática é:

[...] formada por um certo número de aulas planejadas e analisadas previamente com a finalidade de observar situações de aprendizagem, envolvendo os conceitos previstos na pesquisa didática. [...], é preciso estar atento ao maior número possível de informações que podem contribuir no desvelamento do fenômeno investigado. (PAIS, 2011, p. 102)

A análise a priori de uma situação problema é composta, conforme Almouloud (2007), de duas etapas sendo uma matemática e outra didática. Na primeira, verificam-se quais foram os métodos ou estratégias utilizadas pelos discentes durante a resolução de cada situação. Na didática, verifica-se a adequação das situações didáticas aos saberes matemáticos prévios, para tentar antecipar as possíveis dificuldades que podem ser enfrentadas durante a resolução das atividades e por fim antever "os saberes/conhecimentos e/ou métodos de resolução de problemas que devem ser institucionalizados."

A experimentação é a própria aplicação da Sequência Didática é uma etapa fundamental, pois proporciona a comparação entre os resultados práticos e a análise teórica.

Na Análise a posteriori, concordamos com Almouloud (2007), quando este a caracteriza como a observação dos resultados obtidos durante todo o processo de resolução das atividades que proporcionaram a construção de novos conhecimentos. Toda esta análise é pautada pela com-

\author{
plurais


paração do que pretendíamos com estas ações (análise a priori), pelos fundamentos teóricos e todo questionamento da pesquisa.

Segundo Pais (2011) a validação dos resultados obtidos é alcançada pela comparação entre as análises a priori e a posteriori em confrontamento com as hipóteses levantadas no início da pesquisa com rigor científico.

\title{
Metodologia
}

Por se tratar de uma pesquisa social, este artigo tem o caráter qualitativo. Segundo Godoy (1995), uma das várias possibilidades de se estudar os fenômenos que envolvem os humanos e suas imbricadas relações sociais é através da pesquisa qualitativa. A metodologia escolhida foi dividida em três etapas, conforme quadro 01. Inicialmente, através da elaboração e aplicação de entrevista guiada com grupo focal, realizou-se um estudo da população envolvida, onde os três itens estudados foram: perfil, os conhecimentos matemáticos prévios relativos ao tema e às noções básicas de informática dos discentes. Antes de iniciar a entrevista, a professora pediu que um dos discentes lesse em voz alta o Termo de Consentimento Livre e Esclarecido - TCLE, e se tivessem de acordo, que todos preenchessem e assinassem. As informações obtidas através dessa entrevista (grupo focal) serviram como suporte para construção da sequência didática.

Gatti (2012, ps. 12 e 13) compreende o grupo focal como uma técnica de levantamento de dados, ancorada pela dinâmica interacional de um grupo de pessoas, com o suporte de um mediador.

\begin{abstract}
Nesses primeiros momentos, deixa-se claro que todas as ideias e opiniões interessam, que não há certo ou errado, bom ou mau argumento ou posicionamento, que se espera mesmo que surjam diferentes pontos de vista, que não está em busca de consensos. (Gatti, 2012, p. 29)
\end{abstract}

Estas informações obtidas na entrevista foram gravadas, transcritas e depois analisadas. A partir dessa análise, foi elaborada e aplicada uma sequência didática cujo objeto de estudo foi as funções logarítmicas. Durante o processo a Engenharia Didática forneceu subsídios para análise, desde a elaboração da sequência didática, passando pela aplicação e resultados. 
Quadro 01 - Ações Realizadas durante o Experimento

\begin{tabular}{|l|l|}
\hline \multicolumn{1}{|c|}{ AÇÃO } & \multicolumn{1}{c|}{ OBJETIVO } \\
\hline Entrevista Guiada com Grupo Focal & $\begin{array}{l}\text { Avaliar o perfil dos estudantes, e os conhecimentos prévi- } \\
\text { os referentes à Matemática e à Informática. }\end{array}$ \\
\hline Aplicação da Sequência Didática 01 & $\begin{array}{l}\text { Proporcionar a aprendizagem, a partir da manipulação do } \\
\text { Controle Deslizante no GeoGebra, da condição de exis- } \\
\text { tência da Função Logaritmica e o estudo do crescimento/ } \\
\text { decrescimento dessas Funções. }\end{array}$ \\
\hline Análise Através da Engenharia Didática & $\begin{array}{l}\text { Verificar todo o processo desde a elaboração até à aplica- } \\
\text { ção da sequência didática, através da análise } a \text { priori e } a \\
\text { posteriori. }\end{array}$ \\
\hline
\end{tabular}

Fonte: Dados da pesquisa realizada, 2016.

A entrevista guiada foi realizada com quatro grupos focais durante o horário de aula com a participação de 22 discentes da Licenciatura em Matemática.

Nas análises prévias, foram identificados o perfil e os conhecimentos prévios em Matemática e Informática de cada grupo focal. Na construção das situações e análise a priori, foi realizada a escolha das questões abertas e/ou fechadas para compor a sequência didática, de acordo com os resultados obtidos nas entrevistas guiadas.

Após análise da entrevista guiada, foi elaborada uma sequência didática dividida em 3 partes na qual os alunos participaram, de forma individual, e utilizando como suporte tecnológico o GeoGebra. Este artigo irá tratar da primeira parte dessa mesma sequência, conforme apresentado no quadro 02 . 
Quadro 02: Sequência Didática sobre funções Logarítmicas

Ao abrir o software GeoGebra, insira na Janela de Visualização, os "eixos" e as "malhas". Feito isso, com a ferramenta Controle Deslizante, crie o controle deslizante para o parâmetro a. No Campo de Entrada, digite a função $\mathrm{f}(\mathrm{x})=\log (\mathrm{a}, \mathrm{x})$ para representar a função $\mathrm{f}(\mathrm{x})=$ Então, movimente de diversas maneiras o Controle Deslizante para ver o que acontece. Para isso, clique com o botão direito em cima do Controle Deslizante e anime ou, então, faça manualmente. Depois de ter realizado esta movimentação do controle, responda:

PARTE 01:

1. O que acontece quando o valor de a é igual a 1? Por quê? Explique com suas palavras.

2. O que acontece quando o valor de a é igual a zero? Por quê? Explique com suas palavras.

3. O que ocorre quando o valor de a é menor que zero? Por quê? Explique com suas palavras.

4. Para quais valores de a, a função logarítmica é crescente? E quando ela é decrescente? Salve o arquivo com a terminologia: seu nome. ATIV1_PARTE01.ggb

Fonte: Dados da pesquisa realizada, 2016.

\section{Descrição da aplicação das Sequências Didáticas}

Os alunos do primeiro semestre de Licenciatura em Matemática participaram, de forma individual, das atividades realizadas no Laboratório de Informática, onde cada um teve acesso a um computador. Para garantir a segurança dos dados realizados no GeoGebra, todos os arquivos foram salvos na área de trabalho e devidamente enviados para o e-mail da professora e após a checagem dos arquivos recebidos com sucesso, os alunos foram liberados da atividade. Além disso, todas as folhas com a sequência didática foram respondidas e devolvidas à pesquisadora ao final de cada atividade.

A primeira sequência didática foi dividida em três partes, sendo que a primeira aconteceu no dia 16 de novembro de 2016, com uma 1h de duração. Participaram deste encontro dezoito alunos.

\section{Resultados e Discussões}

$\mathrm{Na}$ análise a priori da situação problema, foram verificados quais os métodos e/ou estratégias utilizadas pelos discentes durante a resolução de cada situação e analisado a adequação das 
situações didáticas aos saberes matemáticos prévios. Nesse artigo, apenas o item 4 da Sequência Didática descrita será analisado.

Na questão 4, o intento foi observar se o aluno através da representação gráfica e com o uso do aporte tecnológico do GeoGebra, conseguiu identificar o crescimento e decrescimento da função em relação aos valores de, portanto se implica em uma função crescente, se implica numa função decrescente. $\mathrm{O}$ quadro 03 demonstra as respostas dos oito alunos analisados, cujos nomes foram trocados por índices: A - 01, A -02, A - 03, A - 04, A - 05, A - 06, A - 07 e A - 08, para garantir o anonimato, referente a uma dessas perguntas (quarta) da sequência. A pesquisa iniciou com 22 alunos, mas a análise das respostas seguiu um critério, onde apenas os discentes que participaram de todas as etapas do trabalho foram contemplados e suas respostas foram comentadas e avaliadas.

Quadro 03 - Sequência 01 - Resposta

\begin{tabular}{|l|l|}
\hline Alunos & Resposta fornecida à questão 04 \\
\hline A - 01 & $\begin{array}{l}\text { De } 0 \text { (zero) à 1(um) a função de a é decrescente, a partir de 1.1 é } \\
\text { crescente. }\end{array}$ \\
\hline A - 02 & ela é crescente ela é decrescente. \\
\hline A - 03 & $\begin{array}{l}\text { Quando minha base a tende do 0 a 1 minha função é crescente, } \\
\text { quando a base os valores são maior que 1 a função é decrescente. }\end{array}$ \\
\hline A - 04 & É crescente decrescente. \\
\hline A - 05 & É decrescente de zero (0) a um (1) e crescente de 1.1 a 5. \\
\hline A - 06 & $\begin{array}{l}\text { Ela é crescente quando temos o valor de e para ela ser decrescente } \\
\text { ela tem que estar entre } .\end{array}$ \\
\hline A - 07 & $\begin{array}{l}\text { No intervalo entre (0,1) a função é crescente, quando passa de um } \\
\text { para mais infinito é decrescente. }\end{array}$ \\
\hline A - 08 & $\begin{array}{l}\text { Para temos uma função crescente e para temos uma função } \\
\text { decrescente. }\end{array}$ \\
\hline
\end{tabular}

Fonte: Dados da pesquisa realizada, 2016.

Nesta pesquisa, a Engenharia Didática encontra-se como metodologia de análise dos resultados referentes ao estudo dos processos de ensino de um objeto matemático - Funções Logarítmicas. Depois da construção da Sequência Didática, estas foram aplicadas em encontros de ensino ("sessões 
de ensino"), houve a observação e o registro desses encontros. A análise deste processo ocorreu em duas fases: a priori (caracterizada pela intenção da professora frente ao desenvolvimento das atividades no momento do seu planejamento) e a posteriori (com as respostas dos alunos durante a aplicação das sequências, comparando com a fase anterior).

Com essas oito respostas à questão 04 , podemos verificar que o aluno $\mathrm{A}$ - 06 obteve maior rigor matemático na resposta, o aluno A - 08 também se aproximou muito da resposta correta, quase todos os alunos usaram a linguagem matemática e tiveram autonomia na manipulação do suporte tecnológico, o que pode ser justificado pelos conhecimentos prévios sobre o Logaritmo e o software GeoGebra. A - 06 mostrou-se bastante curioso durante a fase de formulação que é caracterizada pela troca de informação entre o aluno e o meio (o software matemático) durante a atividade, também questionou bastante durante a realização da mesma. Enquanto o aluno A 02 apresentou muitas dificuldades na resolução da questão, mas não procurou a intervenção da professora durante a fase de ação e mesmo usando a linguagem matemática demonstrou muita dificuldade na interpretação da atividade.

\section{Institucionalização da sequência didática 01}

A institucionalização ocorreu no dia 22 de novembro de 2016, no Laboratório de Informática 01, com duração de 1h40min e teve a participação de dezoito alunos. Com o auxílio do GeoGebra, toda esta sequência foi discutida entre a professora e os discentes e a institucionalização do conhecimento sobre a Função Logarítmica ocorreu, de acordo com a TSD. Vale ressaltar algumas informações importantes sobre esse momento didático.

Muitos alunos na atividade não associaram a condição de existência da base de uma função logarítmica, então decidimos partir do exemplo de uma função exponencial, fazer a relação entre as duas funções e verificar porque esta base não poderia ser um número igual a zero, a um ou a real negativo. Assim, tornou-se mais fácil para os discentes se apropriarem desse conhecimento. A análise da representação gráfica no GeoGebra também foi fundamental. Nesse momento, aproveitamos para visualizar a representação de duas funções neste software: a exponencial e a sua respectiva inversa (logarítmica), e mostramos a sua relação de simetria. 
Através da manipulação do Controle Deslizante, provocamos os alunos para descobrir em que intervalos da base a função era crescente ou decrescente. E posteriormente, a professora formalizou esta percepção na lousa.

Em consequência dos alunos terem tido dificuldade em analisar o gráfico que representa a função logarítmica e encontrar o domínio e a imagem da mesma, plotamos alguns exemplos dessas funções no GeoGebra, com o intuito de esclarecer e generalizar este saber matemático. Finalizada a atividade, a professora solicitou que os alunos preenchessem um questionário online com 5 indagações referentes às sequências didáticas aplicadas, ao uso da tecnologia (GeoGebra) e aos ganhos frente ao estudo de Funções Logarítmicas, conforme figuras 01 e 02.

Figura 01 - Questionário Online Final - Parte 01

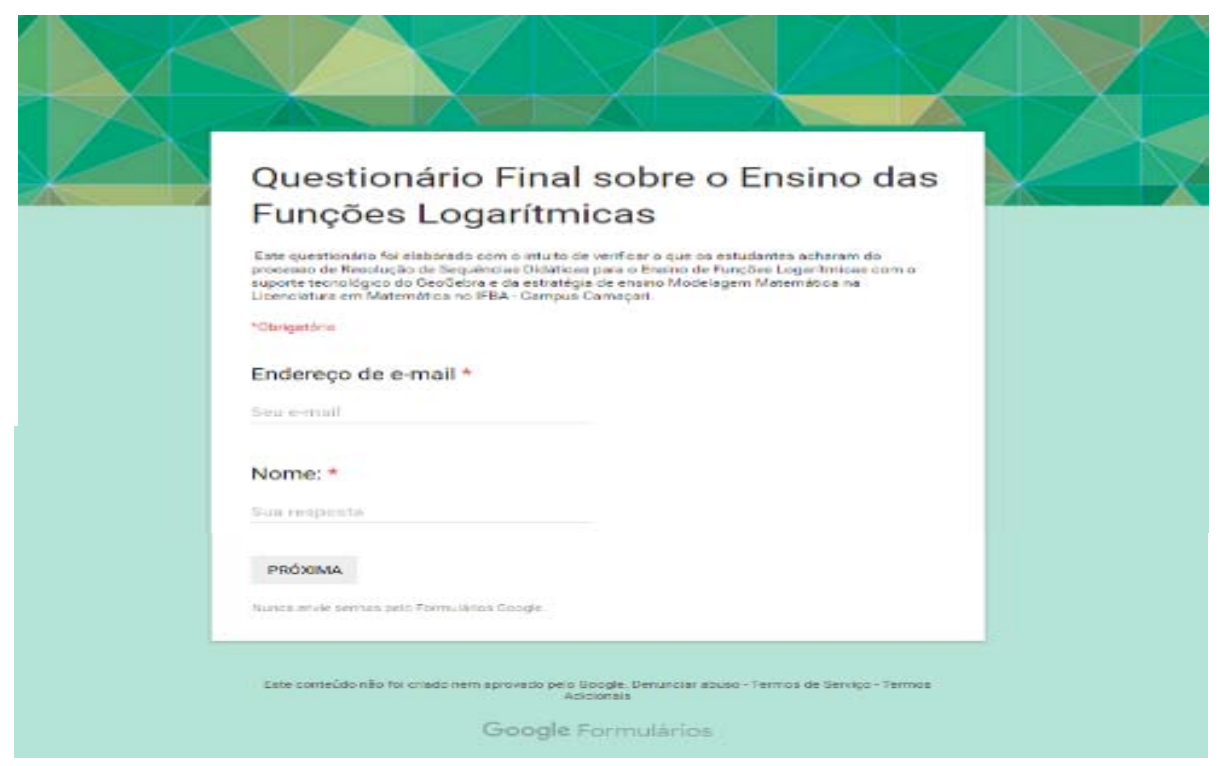

Fonte: Dados da pesquisa realizada, 2016.

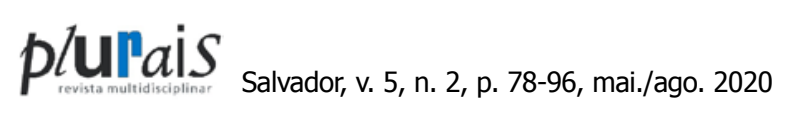


Figura 02 - Questionário Online Final - Parte 02

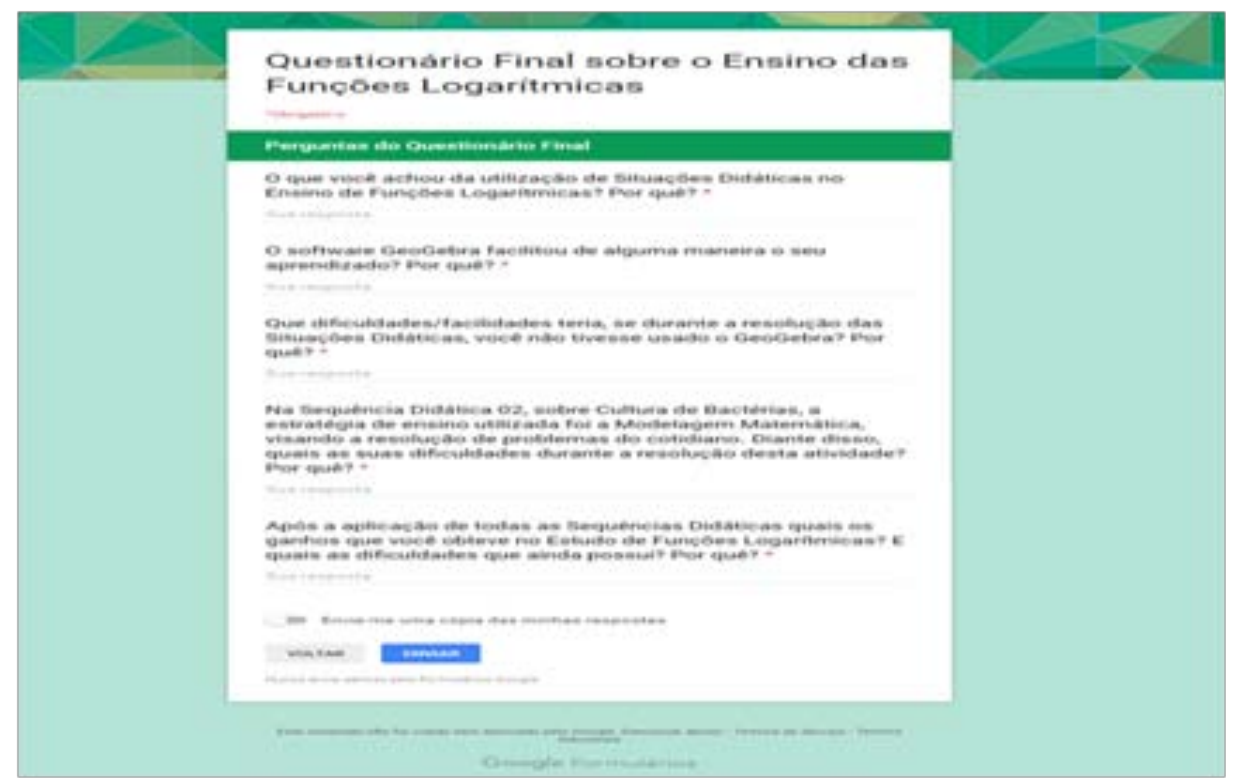

Fonte: Dados da pesquisa realizada, 2016.

Vale salientar algumas perguntas e respostas para que possamos comprovar os resultados. O software GeoGebra facilitou de alguma maneira o seu aprendizado? Por quê? O aluno Sandro respondeu: "Sim. Através do programa foi possível visualizar as formas e gráficos de uma função logarítmica." Enquanto Laura disse: "Com certeza. E esse software é fundamental para o entendimento nesses assuntos. Facilita bastante a visualização dos gráficos, com as animações faz percebermos as mudanças de forma clara, porque sem o auxílio dele eu teria mais dificuldade em relação a responder e entender algumas questões."

Ao ser perguntado sobre que dificuldades/facilidades teria, se durante a resolução das Situações Didáticas, você não tivesse usado o GeoGebra? Por quê? O aluno A - 06 afirmou: "Facilitou na plotagem do gráfico das funções para entendimento do problema." Quando ele foi indagado sobre os ganhos que você obteve no Estudo de Funções Logarítmicas após a aplicação de todas as Sequências Didáticas e quais as dificuldades que ainda se apresentavam, ele relatou que os ganhos que ele obteve "foi poder aliar a teoria a situações práticas, o que tira um pouco de abstração da matemática e nos leva um ganho no aprendizado.”

\section{plurais}

Salvador, v. 5, n. 2, p. 78-96, mai./ago. 2020 


\title{
Considerações finais
}

Diante dos empecilhos encontrados em relação ao estudo da função logarítmica, tais como: localização de pontos no plano cartesiano, dificuldade de entender a linguagem formal da matemática, apropriação das operações de potenciação e de radiciação, a linguagem algébrica e por fim, a representação gráfica; surgiu a necessidade de uma profunda reflexão pedagógica.

A contribuição de Godoy (1995) é assertiva, quando ela afirma que cabe ao pesquisador ir a campo buscar ou "captar" a dinâmica do evento a partir do olhar dos sujeitos (participantes). E foram esses "olhares e falas" dos sujeitos que possibilitaram esse trabalho de pesquisa. Através da pesquisa qualitativa e da entrevista com grupo focal, os pesquisadores tiveram um olhar atento aos conhecimentos prévios dos alunos referente à tecnologia (software GeoGebra) e à matemática (Função Logarítmica) para a partir daí construir uma sequência didática, referendada pela TSD de Guy Brousseau, que vislumbrasse seus objetivos.

As TICs não mudam apenas a forma como nos comunicamos, ou armazenamos dados, ou fazemos compras e nos relacionamos, segundo Lévy (2011), elas alteram a forma de ser e pensar, e consequentemente, a forma de aprender, de representar o pensamento humano e de construir nossa forma de existir. Portanto, para contribuir como ator desse processo em construção com alguns avanços que venham a despertar nos alunos a consciência de que a tecnologia é uma alternativa que já faz parte do nosso dia-a-dia, esse é o fator propulsor que cada educador no mundo contemporâneo deve se conscientizar em busca de uma nova postura na arte de educar, de transformar o conhecimento de forma estimulante, numa necessidade de novos saberes.

O papel do professor não se resume a mero transmissor de conteúdo, e sim, de mediador, provocador, incentivador, permitindo que o aluno através do contato com o objeto do conhecimento possa apreender e elaborar sua própria representação da realidade.

Com o suporte tecnológico, a aplicação da sequência didática e a mediação pedagógica, observou-se nos discentes: o interesse, a motivação, as intervenções, as interações e o conhecimento matemático adquirido. Utilizando como metodologia de análise a Engenharia Didática em todo o processo.

O objetivo desse trabalho se concentra em verificar como o GeoGebra pode potencializar o processo de ensino-aprendizagem da função logarítmica. Dessa forma, a escolha da Teoria

\author{
plurais


das Sequências Didáticas e o uso do GeoGebra não se resume à uma técnica para corroborar na aprendizagem de conteúdos matemáticos, mas é ampliada pela necessidade de formar cidadãos conscientes no seu papel como atores transformadores da sociedade e para isso, precisamos motivar e/ou provocar os alunos para a autodescoberta de forma que eles consigam a autonomia no seu processo de aprender, onde a reflexão e o pensamento crítico seja o objetivo final.

Essa pesquisa é processo permanente que não se finaliza nessa etapa, sendo uma espiral, que tem como objetivo articular discussões dos resultados para reavaliação dos mesmos e até sofrer possíveis modificações, além de acompanhar as futuras turmas onde essa metodologia pode vir a ser aplicada.

Devemos formar alunos críticos, criativos e curiosos diante do saber e se não houver uma mudança didática do processo de ensino-aprendizagem este objetivo dificilmente será alcançado.

\section{REFERÊNCIAS}

ALLEVATO, N. S. G. Utilizando Animação Computacional no Estudo de Funções. Revista de Ensino de Ciências e Matemática - RenCiMa, São Paulo, v. 1, n.2, p. 111-125, 2010. Disponível em: <http://revistapos.cruzeirodosul.edu.br/index.php/rencima/article/viewFile/13/15>. Acesso em: 30 maio 2016.

ALMOULOUD, Saddo Ag. Fundamentos da didática da matemática. Curitiba: UFPR, 2007.

BATISTA, S. C. F.; BARCELOS, G. T.; RAPKIEWICZ, C. E.; HORA, H. R. M. Avaliar é Preciso: o caso de softwares educacionais para Matemática no Ensino Médio. In: Workshop de Ciências da Computação e Sistemas da Informação da Região Sul - WorkComp Sul, 1, 2004, Palhoça, SC. Anais...Palhoça, SC: UNISUL, 2004.

BORBA, M. C.; PENTEADO, M. G. Informática e Educação Matemática. 3. ed. Belo Horizonte: Autêntica. 2003.

BROUSSEAU, G. Introdução ao estudo das situações didáticas: conteúdos e métodos de ensino. São Paulo: Ática, 2008.

D’ÁMBRÓSIO, U. Educação Matemática. 9.ed. Papirus: Campinas, 2012.

GATTI, B. A. Grupo Focal na Pesquisa em Ciências Sociais e Humanas. Brasília: Liber Livro Editora, 2012.

GODOY, A. S. Pesquisa qualitativa: tipos fundamentais. Revista de Administração de empresas, São Paulo, v. 35, n. 3, p. 20-29,1995. 
LÉVY, Pierre. O que é virtual? Tradução: Paulo Neves. 2. ed. São Paulo: 34, 2011.

LIMA, Elon L. et al. A Matemática do Ensino Médio. Rio de Janeiro: SBM, 2006. 308 p. (Coleção do professor de matemática, v.2)

NASSER, Lilian; TORRACA, Marcelo André Abrantes; SOUSA, Geneci Alves de. Aprendizagem de Cálculo: Dificuldades e Sugestões para a Superação. In: XIV Conferência Interamericana de Educación Matemática - CIAEM, 2015, Tuxtla Gutiérrez - Chiapas. XIV Conferência Interamericana de Educación Matemática - CIAEM, 2015.

PAIS, L. C. Didática da Matemática: uma análise da influência francesa. 3. ed. Belo Horizonte: Autêntica, 2011.

POMMER, Wagner Marcelo. SEMA - Seminários de Ensino de Matemática. Brousseau e a idéia de Situação Didática / FEUSP, 2008. Diponível em: http://www.nilsonjosemachado.net/ sema20080902.pdf. Acesso em: 26 ago. 2016.

REIS, F. P. dos. Introdução ao estudo das funções de $1^{\mathbf{0}}$ grau com o uso do software Geo-

Gebra. Trabalho de conclusão de especialização (Instituto de Matemática. Matemática, Mídias Digitais e Didática : tripé para formação do professor de matemática) - Universidade Federal do Rio Grande do Sul, 2015. Disponível em: http://www.lume.ufrgs.br/handle/10183/134091. Acesso em: 28 de julho de 2016.

ROCHA, A. M. C. . Uso do software Winplot para o estudo de Trigonometria. Polyphonia: Revista de Educação Básica do Cepae (UFG) , v. 21, p. 137-151, 2010. Disponível em: https:// www.revistas.ufg.br/sv/article/view/16292 . Acesso em: 28 de julho de 2016.

Recebido em: 10 de julho de 2020.

Inserido em: 10 de agosto de 2020.

Esta obra está licenciada com uma Licença Creative Commons Atribuição 4.0 Internacional. 